\title{
Effect of laparoscopic cholecystectomy on liver enzymes in Arabian goats
}

\author{
Hatim Al-Abbadi ${ }^{1}$ \\ ${ }^{1}$ Department of Surgery, Faculty of Medicine, King Abdulaziz University, Jeddah, Saudi Arabia \\ Hatim A. A. Effect of Laparoscopic Cholecystectomy on Liver Enzymes in Arabian Goats. J Pre-Clin Clin Res. 2019 ; $13(1)$ : 5-8. \\ |DOI:10.26444/jpccr/103430
}

\begin{abstract}
Introduction and objective. Laparoscopic cholecystectomy (LC) has become the gold standard management option for benign gallbladder disease and cholelithiasis. However, there are physiological consequences with the induction of pneumoperitoneum during LC, resulting in the reduction of hepatic blood flow which leads to the elevation of liver enzymes. This study aimed to evaluate changes in liver enzymes after LC and determine its clinical effects on goats.

Materials and method. This prospective study was conducted in six goats via LC using four-trocar procedure to determine alteration in liver enzymes. Vital parameters, including rectal temperature, respiratory rate, and heart rate were monitored twice daily for abnormalities. Blood samples were collected pre-operatively and at 2, 12, and 36 hours, and on day 3 and day 7 after surgery to compare liver enzyme alterations (aspartate transaminase [AST], alanine transaminase [ALT], alkaline phosphatase [ALP], bilirubin, total protein, and albumin).

Results. Average time for LCs was 25 minutes. Biochemical estimation revealed a significant increase $(p \leq 0.05)$ in total (baseline: $0.27 \pm 0.03 \mathrm{mg} / \mathrm{dL}$ vs. at $2 \mathrm{~h}: 0.57 \pm 0.02 \mathrm{mg} / \mathrm{dL}$ and $12 \mathrm{h:} 1.05 \pm 0.20 \mathrm{mg} / \mathrm{dL}$ ) and direct bilirubin (baseline value: $0.12 \pm 0.02 \mathrm{mg} / \mathrm{dL}$ vs. $2 \mathrm{h:} 0.23 \pm 0.02 \mathrm{mg} / \mathrm{dL}$ and $12 \mathrm{h:} 0.23 \pm 0.02 \mathrm{mg} / \mathrm{dL})$. Indirect bilirubin increased significantly $(p \leq 0.05)$ after 12 hours post-operatively. Total protein and globulin decreased significantly $(p \leq 0.05)$ throughout. AST and ALT levels increased ( $p \leq 0.05)$ after $2,12,36$ hours, and on day 3 post-operatively. ALP increased after 2 hours and thereafter decreased significantly $(p \leq 0.05)$.
\end{abstract}

Conclusion. A considerable rise in the liver enzymes of the goat after LC due to changes in hepatic blood flow was observed.

Key words

biochemical changes, laparoscopy, goat, liver enzymes

\section{INTRODUCTION}

Laparoscopic cholecystectomy (LC) was introduced in 1987 and since then has replaced open cholecystectomy (OC). LC has also become the gold standard in the management of benign gallbladder disease and cholelithiasis $[1,2]$. LC is associated with several advantages, including reduced pain, a quick return to normal life, and reduced wound infection [3, 4]. However, there are physiological consequences with the induction of pneumoperitoneum during $\mathrm{LC}$, resulting in the reduction of hepatic blood flow which leads to the elevation of liver enzymes [2,5]. Hence, biochemical estimation of liver enzymes is recommended in common clinical practice [1].

The changes in post-operative liver function tests (LFTs) after LC may also result from the potential hepatotoxicity of anesthetic drugs used during the procedure, and the thermal energy used for haemostatic control during gallbladder removal [6]. For instance, potential hepatocellular damage is identified with the elevation of serum aspartate aminotransferase (AST) and alanine aminotransferase (ALT) $[7,8]$. Increased level of alkaline phosphatase (ALP) is a result of biliary duct obstruction while haemolysis or bile flow obstruction increases bilirubin level. A significant increase in serum transaminase is the implication of common bile duct stones [1]. Indeed, LC is a common procedure performed in human surgical practice.

Address for correspondence: Dr Hatim Al-Abbadi, King Abdulaziz University Hospital, King Abdulaziz University, 21589, Jeddah, Saudi Arabia

E-mail: hatimalabbadi@yahoo.com

Received: 19 November 2018; accepted: 29 January 2019; first published: 21 March 2019

\section{OBJECTIVE}

The aim of this study is to evaluate the changes in liver enzymes after LC, and to determine its clinical effects on goats. In addition, the study also focuses on evaluation of the feasibility and safety of laparoscopy in veterinary surgery, particularly in goats, as anatomically the liver of goats resembles the human liver. The study was carried out on goats using the four-trocar procedure, as performed in humans. The increase in liver enzymes was evaluated at different post-operative periods of time by correlating the changes in LFTs pre- and post-operatively.

\section{MATERIALS AND METHOD}

The present prospective study was conducted on goats to evaluate the effect of laparoscopic cholecystectomy on liver enzymes. The study was conducted in the Experimental Surgery Unit at King Fahd Medical Research Centre, King Abdulaziz University, Jeddah, Saudi Arabia. The study was approved by the Research Ethics Committee, King Abdulaziz University Hospital.

Six Arabian goats, weighing between $20-25 \mathrm{Kg}$ and aged 2-4 years were selected for the study. Goats were fed alfalfa/ grass hay and a commercial diet with free access to water. All the goats were healthy and had no gallstones at the time of study initiation. Food was withheld for 36 hours and water for 12 hours pre-operatively. All goats underwent the same surgical procedure. 
Surgical Procedures. Intravenous propofol at a dose of $4 \mathrm{mg} /$ $\mathrm{Kg}$, was used to facilitate the introduction of endotracheal intubation for inhalation anaesthesia [9]. Anaesthesia was maintained using Isoflurane inhalation during the whole period of each of the surgical procedures. In all the animals' peritoneal cavity, pneumoperitoneum was achieved with $\mathrm{CO}_{2}$ insufflation at a pressure between $13-15 \mathrm{mmHg}$.

The anaesthetized animals were positioned in a dorsal recumbent position, while the table was positioned in antiTrendelenburg position. The goats were rotated upright so that the visceral mass moved downward. This position enabled a good visualization of the visceral aspect of liver and gallbladder of the goats. Anaesthetized goats had four portals for insertion of the four trocars, two of $5 \mathrm{~mm}$ size and the other two trocars of $10 \mathrm{~mm}$ size. The first peritoneal access was achieved via a $10 \mathrm{~mm}$ trocar for the laparoscopy. The trocar was inserted at the ventral midline, just anterior to the umbilicus. The other three trocars were inserted at the paramedian areas as an instrumental portal according to the liver size, and to achieve convenient access to the gallbladder according to surgeon's preference.

A general exploratory laparoscopy was performed initially and nothing abnormal was detected. The gallbladder was then identified and grasped with an endo grasper. The dissection of the cystic duct and vessels was performed using Maryland forceps. The dissection was carried out simultaneously as in goats these structures are adherent to each other. After that, the duct, along with vessels, was clipped with titanium clips and divided. The gallbladder was dissected out from its liver bed using an L-shaped cautery laparoscopic tip until it was removed via a $10 \mathrm{~mm}$ size port. Haemostasis was secured throughout the whole procedure using a cautery. Portal wounds were closed using $2 / 0 \mathrm{Vicryl}$ sutures in continuous closure, followed by their dressing.

Post-operative care. After complete recovery, animals were gradually given access to water and food. Intramuscular Penicillin 20000 I.U., and streptomycin at a dose of $10 \mathrm{mg} /$ $\mathrm{Kg}$ body weight, were administrated for five days postoperatively. Vital parameters, including rectal temperature, respiratory rate, and heart rate were monitored twice daily for abnormalities. Surgical stitches were removed ten days post-operatively.

Follow-up examinations were performed every day after surgery to determine any abdominal skin lesion, or any abnormal discharge from the four portals.

Blood Sampling. Blood samples were collected preoperatively at baseline, and post-operatively at two hours, 12 hours, 36 hours, on day 3 and day 7, for comparison of liver enzyme alterations. Biochemical estimation of liver enzymes (AST, ALT, ALP, bilirubin, total protein and albumin) was performed on blood serum using a spectrophotometer (Randox Laboratories, United Kingdom) according to the manufacturer's instructions.

Statistical analysis. The data obtained were analyzed statistically using a Block design of analysis of variance (ANOVA) with general linear model procedures (GLM) [10]. For means of separation, Duncan's Multiple Range Test (DMRT) was used [11]. Statistical analysis was run through SPSS (version, 16) for Windows [12]. A $p$-value of $\leq 0.05$ was considered statistically significant. All the values were expressed as mean \pm SE (standard error) between duration of estimation time periods.

\section{RESULTS}

The average time for LC in the goats was 25 minutes (range: 20-30 minutes). The procedure was safe and successfully performed without any major complications. All the goats recovered well from anaesthesia and were moved to the observation room on the same day of surgery. All of them were kept under observation, and eight hours after surgery were gradually given access to normal food and water.

Initial post-operative observations revealed mild to moderate abdominal discomfort in four goats, showed as laziness in activity and lying down. A stitch abscess in one goat was also observed which was successfully removed with the routine dressing. There was no change or abnormality observed in vital parameters post-operatively.

Biochemical estimation of liver enzymes. Post-operative levels of liver enzymes were compared with pre-operative baseline levels to evaluate the changes observed before and after the procedure. Biochemical estimation revealed a significant increase $(p \leq 0.05)$ in the total bilirubin (baseline value: $0.27 \pm 0.03 \mathrm{mg} / \mathrm{dL}$ vs. two hours post-operatively: $0.57 \pm 0.02 \mathrm{mg} / \mathrm{dL}$ and 12 hours post-operatively: $1.05 \pm 0.20 \mathrm{mg}$ / $\mathrm{dL}$ ) and direct bilirubin (baseline value: $0.12 \pm 0.02 \mathrm{mg} / \mathrm{dL}$ vs. two hours post-operatively: $0.23 \pm 0.02 \mathrm{mg} / \mathrm{dL}$ and 12 hours post-operatively: $0.23 \pm 0.02 \mathrm{mg} / \mathrm{dL}$ ) after two and 12 hours of surgery (Tab. 1). However, there was no further increase after 36 hours, nor on day 3 and day 7 after surgery. Indirect bilirubin showed a significant increase $(p \leq 0.05)$ after 12 hours post-operatively (pre-surgery: $0.15 \pm 0.02 \mathrm{mg} / \mathrm{dL}$ vs. 12 hours post-surgery: $0.82 \pm 0.19 \mathrm{mg} / \mathrm{dL}$ ) with no significant increase after 36 hours on day 3 , and day 7 . There was a significant decrease $(p \leq 0.05)$ in total protein throughout the experiment (pre-operatively: $7.53 \pm 0.12 \mathrm{mg} / \mathrm{dL}$ vs. Day 7 post-operatively: $6.75 \pm 0.13 \mathrm{mg} / \mathrm{dL}$ ) with the maximum reduction $36 \mathrm{~h}$ postoperatively $(5.68 \pm 0.06 \mathrm{mg} / \mathrm{dL})$. There was no significant change in albumin two hours after surgery; however, there was significant decrease after 12 (baseline $1.90 \pm 0.04 \mathrm{mg} /$ $\mathrm{dL}$ vs. 12 hours post-operatively: $1.72 \pm 0.05 \mathrm{mg} / \mathrm{dL})$ and 36 hours $(1.48 \pm 0.06 \mathrm{mg} / \mathrm{dL})$, day $3(1.48 \pm 0.03 \mathrm{mg} / \mathrm{dL})$ and day $7(1.57 \pm 0.02 \mathrm{mg} / \mathrm{dL})$. In addition, there was a significant decrease $(p \leq 0.05)$ in globulin throughout the experiment.

On estimating the changes observed in LFTs, a significant increase $(p \leq 0.05)$ in AST and ALT levels two hours (AST: 668.67 $\pm 25.36 \mathrm{U} / \mathrm{L}$; ALT: $66.83 \pm 3.43 \mathrm{U} / \mathrm{L}$ ), 12 hours (AST: 589.83 $\pm 73.62 \mathrm{U} / \mathrm{L}$; ALT: $65.50 \pm 4.13 \mathrm{U} / \mathrm{L}$ ), 36 hours (AST: 366.67 $\pm 27.88 \mathrm{U} / \mathrm{L}$; ALT: $53.33 \pm 2.93 \mathrm{U} / \mathrm{L}$ ), and day 3 (AST: 133.00 $\pm 3.76 \mathrm{U} / \mathrm{L}$; ALT: $31.83 \pm 0.77 \mathrm{U} / 004 \mathrm{C}$ ) post-operatively, was observed. However, there was an insignificant change after Day 7. In addition, a significant increase $(p \leq 0.05)$ in ALP after two hours $(179.0 \pm 18.37 \mathrm{U} / \mathrm{L}$ vs. $202.17 \pm 2.33$ $\mathrm{U} / \mathrm{L})$ followed by a significant decrease $(p \leq 0.05)$ after 12 hours (122.50 $\pm 1.55 \mathrm{U} / \mathrm{L}), 36$ hours $(86.33 \pm 1.43 \mathrm{U} / \mathrm{L})$, Day 3 $(67.50 \pm 4.10 \mathrm{U} / \mathrm{L})$, and Day $7(126.67 \pm 14.73 \mathrm{U} / \mathrm{L})$ after surgery was observed (Tab. 2).

Safety. Safety precautions were taken during the procedure and the goats were monitored for any reactions. No adverse reaction was observed neither during nor after the completion of the surgical procedure. 
Table 1. Biochemical Parameters with Laparoscopic Cholecystectomy

\begin{tabular}{|c|c|c|c|c|c|c|}
\hline Duration of Estimation & Total Bilirubin (mg/dL) & Direct Bilirubin (mg/dL) & Indirect Bilirubin (mg/dL) & T. protein $(\mathrm{g} / \mathrm{dL})$ & Albumin (g/dL) & Globulin (g/dL) \\
\hline Baseline (pre-operatively) & $0.27 \pm 0.03$ & $0.12 \pm 0.02$ & $0.15 \pm 0.02$ & $7.53 \pm 0.12$ & $1.90 \pm 0.04$ & $5.63 \pm 0.16$ \\
\hline $2 \mathrm{~h}$ post-operatively & $0.57 \pm 0.02$ & $0.23 \pm 0.02$ & $0.33 \pm 0.02$ & $7.08 \pm 0.14$ & $1.83 \pm 0.03$ & $5.25 \pm 0.17$ \\
\hline $12 \mathrm{~h}$ post-operatively & $1.05 \pm 0.20$ & $0.23 \pm 0.02$ & $0.82 \pm 0.19$ & $6.72 \pm 0.22$ & $1.72 \pm 0.05$ & $5.00 \pm 0.25$ \\
\hline $36 \mathrm{~h}$ post-operatively & $0.52 \pm 0.04$ & $0.17 \pm 0.02$ & $0.35 \pm 0.03$ & $5.68 \pm 0.06$ & $1.48 \pm 0.06$ & $4.20 \pm 0.04$ \\
\hline Day 3, post-operatively & $0.32 \pm 0.03$ & $0.12 \pm 0.02$ & $0.20 \pm 0.03$ & $6.08 \pm 0.09$ & $1.48 \pm 0.03$ & $4.60 \pm 0.08$ \\
\hline Day 7 post-operatively & $0.30 \pm 0.00$ & $0.10 \pm 0.00$ & $0.20 \pm 0.00$ & $6.75 \pm 0.13$ & $1.57 \pm 0.02$ & $5.18 \pm 0.11$ \\
\hline
\end{tabular}

All values are expressed

as mean $\pm \mathrm{SE}$ (standard

error); Between duration of

estimation time periods, the $p$

values varied significantly as

$p=0.0001(p \leq 0.01)$

Table 2. Liver enzyme activity with laparoscopic cholecystectomy

\begin{tabular}{lccc}
\hline Duration of Estimation & AST $(\mathrm{U} / \mathrm{L})$ & ALT $(\mathrm{U} / \mathrm{L})$ & ALP $(\mathrm{U} / \mathrm{L})$ \\
\hline Baseline (pre-operatively) & $56.83 \pm 1.17$ & $19.33 \pm 0.49$ & $179.0 \pm 18.37$ \\
\hline 2 h post-operatively & $668.67 \pm 25.36$ & $66.83 \pm 3.43$ & $202.17 \pm 2.33$ \\
\hline 12 h post-operatively & $589.83 \pm 73.62$ & $65.50 \pm 4.13$ & $122.50 \pm 1.55$ \\
\hline 36 h post-operatively & $366.67 \pm 27.88$ & $53.33 \pm 2.93$ & $86.33 \pm 1.43$ \\
\hline Day 3, post-operatively & $133.00 \pm 3.76$ & $31.83 \pm 0.77$ & $67.50 \pm 4.10$ \\
\hline Day 7, post-operatively & $57.50 \pm 4.86$ & $15.00 \pm 0.77$ & $126.67 \pm 14.73$
\end{tabular}

All values have been expressed

as mean $\pm \mathrm{SE}$ (standard error);

between times, the $p$ values

differed significantly as $p=0.0001$

$(p \leq 0.01)$ AST - Serum Aspartate

Aminotransferase; ALT - Alanine

Aminotransferase; ALP - Alkaline

Phosphatase

\section{DISCUSSION}

LC has become the most common therapeutic tool in surgery for the treatment of cholelithiasis and cholecystitis [13]. However, it is not the gold standard as it is associated with numerous adverse effects (AEs), such as duct injuries and obstructions. As such obstructions and injuries are associated with the alteration in liver function and enzymes, it is essential to assess the LFTs post-operatively [14]. Besides iatrogenic injuries, duct obstructions and retained stones, LFTs may show elevation of the liver enzymes due to hepatic dysfunction resulting from increased pneumoperitoneum pressure formed during the surgery $[15,16]$. Other possible reasons include an increase in pressure in the abdomen, squeezing effect on the liver, excessive diathermy (heat energy) used during the procedure, and pulling effect on the gallbladder [17].

In the presented study, there was a transient increase $(p \leq 0.05)$ in AST and ALT levels two, 12, 36 hours, and Day 3 post-operatively, which returned to their normal values after Day 7. In addition, there was a significant increase $(p \leq 0.05)$ in the total and direct bilirubin after two and 12 hours post-operatively, but no further increase after 36 hours, which shows that these biochemical changes seem to be clinically silent.

Similar results were reported in another study which evaluated two techniques of subtotal laparoscopic cholecystectomy in 24 adult female goats. The LFTs showed a significant elevation $(p<0.05)$ in ALP and the total bilirubin values in one of the techniques due to liver injury during the cystic duct and artery dissection [13]. The main reason for the elevation was the use of diathermy for haemostatic control. Another study showed that LC was safe and was successfully performed without any complications for uncomplicated gallbladder disorder in a multi-institutional case series in 20 dogs. The study further reported no morbidities in the dogs [18]. While conventional LC has been reported to be safe according to previously conducted studies, a newer variant which uses hydro jet technology with improved anatomical dissection and bloodless operating fields has also shown no post-operative complications. A study evaluating this procedure on 30 pigs was successfully p[erformed with decreased dissection-related complications in LC [19]. Further, the study showed that the dissection of fibrous and connective tissue preserving blood vessels may be a better technique than conventional LC.

While there are fewer animal studies, the procedure has also been studied in humans. A study evaluating the changes in ALT, AST and ALP in 86 patients who had undergone LC, compared to OC, showed a significant increase in AST and $\operatorname{ALT}(p=0.0001)$, but no significant change in $\operatorname{ALP}(p=0.131)$ [20]. Another study conducted in 100 patients showed that a higher number of patients demonstrated a rise in ALT $(p=0.0001)$ and AST $(p=0.0004)$ in the LC group, compared to the OC group [21]. Halevy et al demonstrated a 1.8-fold increase in AST in 53 patients (79\%) and a 2.2-fold increase in ALT in 55 patients (82\%) which returned to normal within 72 hours [17]. Similarly, the level of serum AST and ALT increased significantly during 24-48 hours after LC in another study of 81 patients $(p<0.0001)$, but the levels were in the normal range three days after surgery in 69 patients [6].

In the presented study, the goats were given two antibiotics (penicillin and streptomycin) post-surgery. According to literature, antibiotics may also lead to drug-induced liver injury. However, streptomycin does not exhibit hepatotoxicity, while penicillin may lead to primary hepatocellular injury in patients at a very low frequency $(0.5-3$ per 100,000 prescriptions). Therefore, the increase in liver enzymes levels may not be due to antibiotics [22]. 


\section{CONCLUSIONS}

The results of the presented study demonstrate a considerable rise in the liver enzymes of the goat after LC. The procedure affected AST, ALT, total and direct bilirubin because of a negative effect on the pneumoperitoneum, due to changes in hepatic blood flow and a small injury to the biliary system. However, the changes of LFTs were clinically silent and transient in normal liver function. Care should be taken before deciding to perform LC in patients with hepatic insufficiency. Overall, the procedure is safe without any morbidity and mortality rate.

\section{REFERENCES}

1. Ahmad N. Routine Testing of Liver Function Before and After Elective Laparoscopic Cholecystectomy: Is It Necessary? JSLS. 2011; 15(1): 65-69. doi: 10.4293/108680811X13022985131291

2.Al-Luwalzi KR, Hamad SO. Changes of liver enzymes and serum bilirubin after laparoscopic cholecystectomy. Ann Coll Med Mosul. 2013; 39(2): 113-117.

3. Coccolini F, Catena F, Pisano M, Gheza F, Fagiuoli S, Di Saverio S, et al. Open versus laparoscopic cholecystectomy in acute cholecystitis. Systematic review and meta-analysis. Int J Surg. 2015; 30: 196-204. doi: 10.1016/j.ijsu.2015.04.083

4. Tauro LF, Sheethal CM, Aithala PSM. Evaluation of Effects of Laparoscopic Surgery on Hepatic Function. J Clin Diagn Res. 2008; 2: 1155-1162. doi: 10.9790/0853-1608012228

5. Koirala R, Shakya VC, Khania S. Rise in liver enzymes after laparoscopic cholecystectomy: a transient phenomenon. Nepal Med Coll J. 2012; 14(3): 223-226.

6. Neri V, Ambrosi A, Fersini A, Tartaglia N, Cianci P, Lapolla F, et al. Laparoscopic cholecystectomy: evaluation of liver function tests. Ann Ital Chir. 2014; 85(5): 431-437.

7. Fikry A. Elevated Liver Enzymes in Patients with Cholecystitis. J Surg. 2014; 2(3): 38-41. doi: 10.11648/j.js.20140203.11
8. Hasukic S, Kosuta D, Muminhodzic K. Comparison of postoperative hepatic function between laparoscopic and open cholecystectomy. Med Princ Pract. 2005; 14: 147-150.

9. Reid J, Nolan AM, Welsh E. Propofol as an induction agent in the goat: a pharmacokinetic study. J Vet Pharmacol Ther. 1993; 16(4): 488-493.

10. Hinkelmann K, Kempthorne O. Design and Analysis of Experiments Set. 2nd ed. John Wiley \& Sons; 2008.

11. Duncan DB. Multiple range and multiple F tests. Biometrics. 1955; 11 : $1-42$.

12. Neudecker J, Sauerland S, Neugebauer E, Bergamaschi R, Bonjer HJ, Cuschieri A, et al. The European Association for endoscopic surgery clinical practice guideline on the pneumoperitoneum for laparoscopic surgery. Surg Endosc. 2002; 16(7): 1121-43.

13. Alkhilani MA, Eesa MJ, Saleh SI, Ajeel AA. A comparative study between two techniques of subtotal laparoscopic cholecystectomy in goats. Iraqi J Vet Med. 2014; 38(2): 114-122.

14. Jarvinen $\mathrm{H}$. Abnormal liver function tests in acute cholecystitis; the predicting of common duct stones. Ann Clin Res. 1978; 10(6): 323-327.

15. Williams MD, Murr PC. Laparoscopic insufflation of the abdomen depresses cardiopulmonary function. Surg Endosc. 1993; 7(1): 12-16.

16. Marathe US, Lilly RE, Silvestry SC, Schauer PR, Davis JW, Pappas TN, et al. Alterations in hemodynamics and left ventricular contractility during carbon dioxide pneumoperitoneum. Surg Endosc. 1996; 10(10): 974-978.

17. Halevy A, Gold-Deutch R, Negri M, Lin G, Shlamkovich N, Evans S, et al. Are elevated liver enzymes and bilirubin levels significant after laparoscopic cholecystectomy in the absence of bile duct injury? Ann Surg. 1994; 219(4): 362.

18. Scott J, Singh A, Mayhew PD, Brad Case J, Runge JJ, Gatineau M, et al. Perioperative Complications and Outcome of Laparoscopic Cholecystectomy in 20 Dogs. Vet Surg. 2016; 45(S1). doi: 10.1111/ vsu. 12534

19. Shekarriz H, Shekarriz B, Upadhyay J, Comman A, Markert U, Bürk CG, et al. Hydro-Jet assisted laparoscopic cholecystectomy: initial experience in a porcine model. JSLS. 2002; 6(1): 53.

20. Guven HE, Oral JS. Liver Enzyme Alterations after Laparoscopic Cholecystectomy. Gastrointestin Liver Dis. 2007; 16(4): 391-394.

21. Hasukic S, Kosuta D, Muminhodzic K. Comparison of Postoperative Hepatic Function between Laparoscopic and Open Cholecystectomy. Med Princ Pract. 2005; 14(3): 147-150. doi: 0.1159/000084630

22. Andrade RJ, Tulkens PM. Hepatic safety of antibiotics used in primary care. J Antimicrob Chemother. 2011; 66: 1431-1446. doi: 10.1093/jac/ dkr159 